\title{
Relations between Catharanthine Content Enhancement with the Other Associated Secondary Metabolites in Catharanthus Roseus Cell Culture that Treated Tryptophan
}

\author{
Dingse Pandiangan ${ }^{1}$, WennyTilaar ${ }^{2}$, Nelson Nainggolan ${ }^{3}$, Lalu Wahyudi ${ }^{4}$ \\ ${ }^{1,4}$ Department of Biology Sam Ratulangi University Manado Indonesia \\ ${ }^{2}$ Department of Agronomy Sam Ratulangi University Manado Indonesia \\ ${ }^{3}$ Department of MathematicSam Ratulangi University Manado Indonesia
}

\author{
(Dingse Pandiangan, Jl. Kampus Kleak Manado, Department of Biology Sam Ratulangi University Manado North \\ Sulawesi Indonesia)
}

\begin{abstract}
This research was part of a strategy to improve the content of catharanthine. One strategy used was the addition of tryptophan as a precursor. Increased content of catharanthine was essential in in vitro culture in order to keep the catharanthine content at least equal to those grown in nature (in vivo). The research was conducted in the laboratory using MS medium with tryptophan 50-250 mg/L. Results of the determination of secondary metabolites at C. roseus cell aggregates showed that the IAAcontent has optimum with $150 \mathrm{mg} / \mathrm{L}$ tryptophan treatment. Tryptophan treatment could increase the content of IAA. Tryptamine content in C. roseus aggregate cells increased with increasing concentrations of tryptophan treatment. Vindoline content in $C$. roseus aggregate cells after 14 days culture decreased by treatment with 100 to $200 \mathrm{mg} / \mathrm{L}$ tryptophan treatment. The increase occurred in $\mathrm{E}(250 \mathrm{mg} / \mathrm{L})$ of 9.71 $\pm 0.20 \mu \mathrm{g} / \mathrm{g} d w$ in Erlenmeyer and $C(150 \mathrm{mg} / \mathrm{L})$ of $11.83 \pm 1.01 \mu \mathrm{g} / \mathrm{g} d w$ in the bioreactor. Catharanthine content of C. roseus aggregate cells after 14 days of culture was increasing and has optimum content in treatment $C(150 \mathrm{mg} / \mathrm{L})$ that was equal to $50.96 \mu g / g$ dw. The content of vinblastine in $C$. roseus aggregates cells until day 14 day culture is not detected. But after day 21 of culture vinblastine content detected and has increased as a result of tryptophan precursor treatment. The relationship between other secondary metabolites with catharanhtine content there are 2 correlation. The negative correlation or antagonist that was vindoline. The positive correlation or synergistic ie tryptamine and IAA, vinblastine after being treated tryptophan.
\end{abstract}

Key words: Secondary Metabolite, Catharanthine, Tryptophan, Precursor

\section{Introduction}

Production of vinca alkaloids and catharanthines have been performed in vitro. But the content of alkaloids and catharanthine fluctuated according to the type of bioactive produced. Therefore, the strategy of increasing the content of alkaloids and catharanthinehave been tested by various methods such as the addition of precursors, elicitation and immobilization (Pandianganet al., 2008). The third strategy was by the addition of a precursor improvement can be sustained, because the cells grew well but catharanthine content can be increase also.

Pandianganet al. (2008a), Pandiangan, (2011), Pandiangan and Nainggolan, (2006a and 2006b) reported that the production of precursors catharanthine with the addition of tryptophan can promote and sustain cell growth while increasing catharanthine content vinca in aggregate cultured cells. Therefore, the authors recommend the addition of precursors to be used on an industrial scale because of cell survival. However, from the results of test effectiveness of anticancer activity of plant extracts and intact vinca results of in vitro culture or tissue culture indicate a difference in the alleged anti-cancer activity changes the content of secondary metabolites such as vinlastine or vincristine (commercial anticancer) in vitro culture. It is evident from the test results anticancer activity of plant extracts and aggregates intact cells decreased (Pandianganet al., 2009).

C. roseus ability to convert precursor tryptophan into several secondary metabolites due to the TDC genes that regulate the activity of tryptophan decarboxylase to convert tryptophan into tryptamine (Thomas et al., 1995). Tryptamine suffered the fate of several possibilities. One section will synthesize IAA and some synthesize catharanthine and other indole alkaloids such as Vindoline, Ajmalisine, Vinblastine and Vincristine (OksmanCaldentey, et al., 2007). How is the relationship between the increase in the content of catharanthine with the presence of other secondary metabolites such as, Vindolinee, Vinblastine and Tryptamine, and other metabolites in cell culture vinca can influence each other, then this research.

Primacy or importance of this research plan is due to the presence of cancer is very much right now, need to transfer production of medicinal plant use tenic intact with the use of bioreactors or tissue culture, the presence of technology in vitro anticancer bioactive compounds to produce a better and any methods efficient to produce anti-cancer drugs, this study is very urgent to be done. Besides it is known to increase the relationship of a particular anticancer metabolite conjunction with other compounds in the culture. 


\section{International Journal of Science and Research (IJSR) \\ ISSN (Online): 2319-7064}

Index Copernicus Value (2013): 6.14 | Impact Factor (2014): 5.611

\section{Research Methods}

Callus was induced in MS medium with plant growth regulator (PGR) $2 \mathrm{mg} / \mathrm{L} \mathrm{2,4-D}$ and $0.2 \mathrm{mg} / \mathrm{L}$ kinetin. After the callus age of 4 weeks, callus separated from leaf explants and transferred to a new medium with the same composition with the previous medium. When the 8 -week-old callus, callus was transferred to the production medium, ie MS solid is added PGR $2 \mathrm{mg} / \mathrm{L}$ NAA and $0.2 \mathrm{mg} / \mathrm{L}$ kinetin. After the age of 12 weeks, callus subcultured into medium containing tryptophan, which is coupled with a solid MS medium with NAA plant growth regulator composition of 2 $\mathrm{mg} / \mathrm{L}$ kinetin and $0.2 \mathrm{mg} / \mathrm{L}$ is the same as the previous production medium. The parameters measured were appearance callus morphology and morphological observation and qualitative.

After the first subculture of callus from reaching the age of 12 weeks, then the next stage is to subculture into liquid culture medium, by removing 1 to 2 grams of callus into Erlenmeyer flask containing $100 \mathrm{~mL}$ of $50 \mathrm{~mL}$ of MS liquid medium with the same combination with medium PGR callus production. Liquid cultures of $C$. roseus cell aggregates agitated at $120 \mathrm{rpm}$ (rotation per minutes) in open space conditions and incubated at room temperature. Performed after the second subculture of $C$. roseus cell aggregates in liquid medium first stage was 2 weeks, that is by replacing the old MS liquid medium with the new MS liquid medium as much as $50 \mathrm{~mL}$. After the $C$. roseus cell aggregates of repeated subculture of the obtained cell suspension cultures. Subcultured suspension culture that has reached the age of 10 days of culture, the cells are ready to be moved into the Erlenmeyer flask containing medium with tryptophan and it's contrrol variations. Observation variable is the presence of cells that grow well with the appearance of increased cell suspension and not having much browning and cell lysis.

Cell cultures are separated from the media, then the media the rest of the cells are dried using blotting paper in a sterile pretridish, then weighed. Culture vessels used were $100 \mathrm{~mL}$ Erlenmeyer flask. Each Erlenmeyer flask containing $25 \mathrm{~mL}$ of liquid MS medium with the same PGR combination with callus production medium but without agar. Subcultures in Erlenmeyer with tryptophan treatment $0(\mathrm{~K}), 50(\mathrm{~A}), 100$ (B), 150 (C), 200 (D), 250 (E) $\mathrm{mg} / \mathrm{L}$ performed directly at the time of the second subculture. 4 replicates of each treatment were made. Heavy inoculum used in cultures in Erlenmeyer was $2 \mathrm{~g}$ of cells. Cells were weighed aseptically in Laminar Air Flow while subculture.

Callus samples that have been dried by freeze dryer as much as $0.1 \mathrm{~g}$ dw extracted by using the method Pandiangan, et al. (2006a). Callus samples dried, then crushed with a mortar and dissolved in $10 \mathrm{~mL}$ of methanol analytical. Samples were agitated for 4 hours at a speed of $120 \mathrm{rpm}$. Mixture of methanol and the precipitate is separated, then the methanol extract was evaporated to dryness at a temperature of $25^{\circ} \mathrm{C}$ for 24 hou. Evaporation the residue was acidified with $0.3 \mathrm{~N}$ $\mathrm{HCl}$ to reach a $\mathrm{pH}$ of 1.5 and then extracted with $10 \mathrm{~mL}$ of dichloromethane. Acid phase was then basified by adding 4 $\mathrm{M} \mathrm{NaOH}$ up to $\mathrm{pH} \mathrm{11,} \mathrm{then} \mathrm{extracted} \mathrm{with} 10 \mathrm{~mL}$ dichloromethane 2 times. Dichloromethane fraction was evaporated in a temperature of $25^{\circ} \mathrm{C}$ during the day. Evaporation the residue was dissolved in $2 \mathrm{~mL}$ of methanol and prepared for HPLC analysis.

Determination of the content of catharanthine performed using High Performance Liquid Chromatography (HPLC). Mobile phase used as eluent was a solution consisting of methanol, acetonitrile, and $5 \mathrm{~mm}$ diammonium hydrogen phosphate in the ratio $3: 4: 3$ is isocratic. The flow velocity of $1 \mathrm{~mL} / \mathrm{min}$. Type column used was shimpak VP-ODS C18 $150 \times 4.6 \mathrm{~mm}$ at a wavelength of $220 \mathrm{~nm}$. The qualitative analysis is done by comparing the retention time of the sample with a standard catharanthine under the same conditions. If there are compounds that have the same retention time with standard catharanthine, then the compound is catharanthine. Quantitative analysis was done by converting the sample area and an area of standards of known concentration (Pandiangan, et al., 2006a).

Catharanthine, tryptamine, vindoline and vinblastine curve standard obtained by making a standard solution of 100 $\mathrm{mg} / \mathrm{mL}$ as a stock solution, then made a series of standard solutions of concentrations of 6.75 to $50 \mathrm{mg} / \mathrm{mL}$ were correlated with the results area of High Performance Liquid Chromatography (HPLC). Based on the results of HPLC made catharanthine standard curve and regression equation that describes the relationship between the concentration of the standard catharanthine area (Pandiangan, et al., 2006).

\section{Results and Discussion}

The applied of some tryptophan precursorconcentrations affect the content of secondary metabolites from cell aggregate culture $C$. roseus. Effect of the tryptophan precursor to the catharanthine content can be determined by observations of secondary metabolites associated among others, the IAA, tryptophan,tryptamine, catharanthine, vindoline and vinblastine.

Secondary metabolites were observed in vincaaggregate cell that cultured with added tryptophan was present in the cells tryptophan, IAA, tryptamine, vindoline, catharanthine and vinblastine tryptophan likewise analyzed to determine the mechanism of the tryptophan absorption and changes in cell aggregate footprint in TIA biosynthesis and catharanthine .

The relationship between the observed variables catharanthine content can be known through correlation analysis through Statistica program. Large correlation coefficients of each parameter were observed in $C$. roseus aggregate cells treated with tryptophan in the culture flask after 14 days can be seen in Table 1 . All variables correlated with the observed variables other, more specifically catharanthine content against other variables. It is important to clarify the relationship between each parameter in favor an increase of catharanthine contentin cultured vinca aggregate cells.

Treatment tryptophan containing catharanthine positively correlated. An increase of 0.43 catharanthine occur every 1 treatment tryptophan. Relations with heavy-wet, protein, TDC, IAA TRN and TRP has a large positive correlation with a correlation coefficient of $0.74 ; 0.14 ; 0.37 ; 0.83 ; 0.77$

\section{Volume 4 Issue 11, November 2015}




\section{International Journal of Science and Research (IJSR) \\ ISSN (Online): 2319-7064 \\ Index Copernicus Value (2013): 6.14 | Impact Factor (2014): 5.611}

and 0.10 respectively. But catharanthine correlation with $\mathrm{PO}$ and vindoline has a negative correlation with a correlation coefficient -0.46 and- 0.56 . The results of this correlation analysis shows that increasing the content catharanthine relationship is the content of IAA, tryptamine, and wet weight, while the lower levels PO activity and vindoline content shows the catharanthine content increased.

Table 1: The correlation between catharanthine content with variable other observations of vinca $(C$. roseus $)$ aggregate cells in the media treatment of 50,100,150, 200 and $250 \mathrm{mg} / \mathrm{L}$ at day 14 after culture.

\begin{tabular}{|c|c|c|c|c|c|c|c|c|c|c|}
\hline & $\begin{array}{c}\text { Treat- } \\
\text { ment }\end{array}$ & $\begin{array}{c}\text { Wet } \\
\text { weight }\end{array}$ & Protein & PO & TDC & IAA & $\begin{array}{c}\text { Vindo- } \\
\text { lin }\end{array}$ & $\begin{array}{c}\text { cathar } \\
\text { anthin } \\
\text { e }\end{array}$ & $\begin{array}{c}\text { Trypa } \\
\text { mine }\end{array}$ & TRP \\
\hline Treatment & 1,00 & $-0,26$ & 0,94 & $-0,86$ & 0,97 & $-0,13$ & 0,14 & 0,43 & 0,97 & 0,91 \\
\hline Wet weight & $-0,26$ & 1,00 & $-0,54$ & 0,17 & $-0,27$ & 0,94 & $-0,93$ & 0,74 & $-0,11$ & $-0,50$ \\
\hline Protein & 0,94 & $-0,54$ & 1,00 & $-0,78$ & 0,92 & $-0,39$ & 0,46 & 0,14 & 0,84 & 0,97 \\
\hline PO & $-0,86$ & 0,17 & $-0,78$ & 1,00 & $-0,71$ & 0,03 & $-0,12$ & $-0,46$ & $-0,90$ & $-0,67$ \\
\hline TDC & 0,97 & $-0,27$ & 0,92 & $-0,71$ & 1,00 & $-0,17$ & 0,13 & 0,37 & 0,90 & 0,94 \\
\hline IAA & $-0,13$ & 0,94 & $-0,39$ & 0,03 & $-0,17$ & 1,00 & $-0,88$ & 0,83 & 0,02 & $-0,42$ \\
\hline Vindoline & 0,14 & $-0,93$ & 0,46 & $-0,12$ & 0,13 & $-0,88$ & 1,00 & $-0,76$ & $-0,04$ & 0,45 \\
\hline Catharanthie & 0,43 & 0,74 & 0,14 & $-0,46$ & 0,37 & 0,83 & $-0,76$ & 1,00 & 0,56 & 0,10 \\
\hline Trypamine & 0,97 & $-0,11$ & 0,84 & $-0,90$ & 0,90 & 0,02 & $-0,04$ & 0,56 & 1,00 & 0,77 \\
\hline TRP & 0,91 & $-0,50$ & 0,97 & $-0,67$ & 0,94 & $-0,42$ & 0,45 & 0,10 & 0,77 & 1,00 \\
\hline
\end{tabular}

The correlation between variables catharanthine content with other observations on vinca aggregate cells ( $C$. roseus) precursor tryptophan in the media treatment of $50,100,150$, 200 and $250 \mathrm{mg} / \mathrm{L}$ in the airlift bioreactor on day 14 after culture. The relationship between PO activity and vindoline with catharanthine content also showed a negative correlation in both the flask and bioreactor. The correlation between $\mathrm{PO}$ and vindoline against catharanthine at -0.46 and -0.76 for Erlenmeyer, whereas in the bioreactor are -0.60 and -0.53 .

The conclusion that many factor that play a role in increasing the catharanthine content of tryptophan treated with $50-250 \mathrm{mg} / \mathrm{L}$ in airlift bioreactor. Factors found from this study are positively associated protein contribute 0.48 , wet weight (biomass) of $0.65,0.07$ TDC activity, PGRof IAA 0.77 , contains tryptophan which accumulates in the cell aggregates 0.84 , the number compounds were detected 0.25 . The role of these factors occurred on day 14 after culture in the bioreactor. In contrast to day 10 after culture in the bioreactor, the role each factor plays a role similar to the culture in a flask on day 14 (Table 1). The role and content of tryptamine TDC activity showed a positive or encouraging an increase catharanthine. Positive role tryptamine 0.56 and 0.37 TDC activity in bioreactor cultures after 10 days of culture, but rather lower on day 14 .

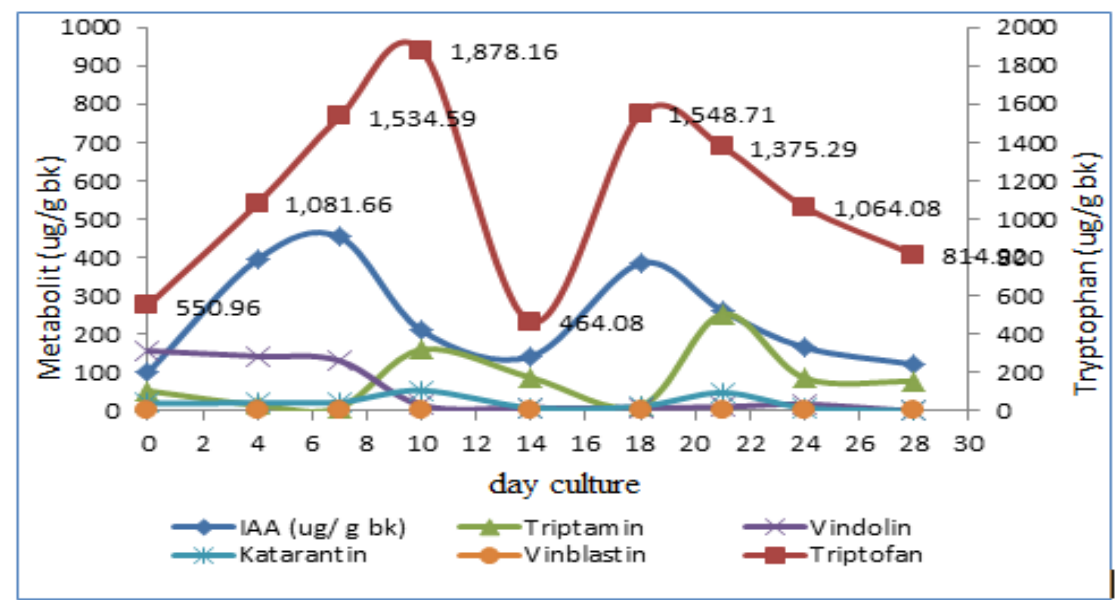

Figure 1: Graph metabolite content $(\mu \mathrm{g} / \mathrm{g} \mathrm{dwdw})$ of vinka cell aggregates (C. roseus) in Erlenmeyer control (no treatment tryptophan).

Factors determining the content of a culture catharanthine optimum. Figure 1 shows that the content of catharanthine observations from day 0 to 28 in agergat control cells (T0) showed a pattern catharanthine maximum levels occurred on days 10 and 21 after subcultured on media control. But at T3 (treatment tryptophan) content of optimum catharanthine actually shifted to day 14 (Figure 2). This confirms the results of the phase II that catharanthine production pattern shifted after treatment precursor tryptophan. The content of other metabolites or pattern also fluctuated during the same 


\section{International Journal of Science and Research (IJSR) \\ ISSN (Online): 2319-7064 \\ Index Copernicus Value (2013): 6.14 | Impact Factor (2014): 5.611}

28-day culture with changing patterns of catharanthine. Therefore catharanthine production in Erlenmeyer should be day 14 and day 10 in biorector airlift volume of $1.5 \mathrm{~L}$. This is a suggestion for the next activity.

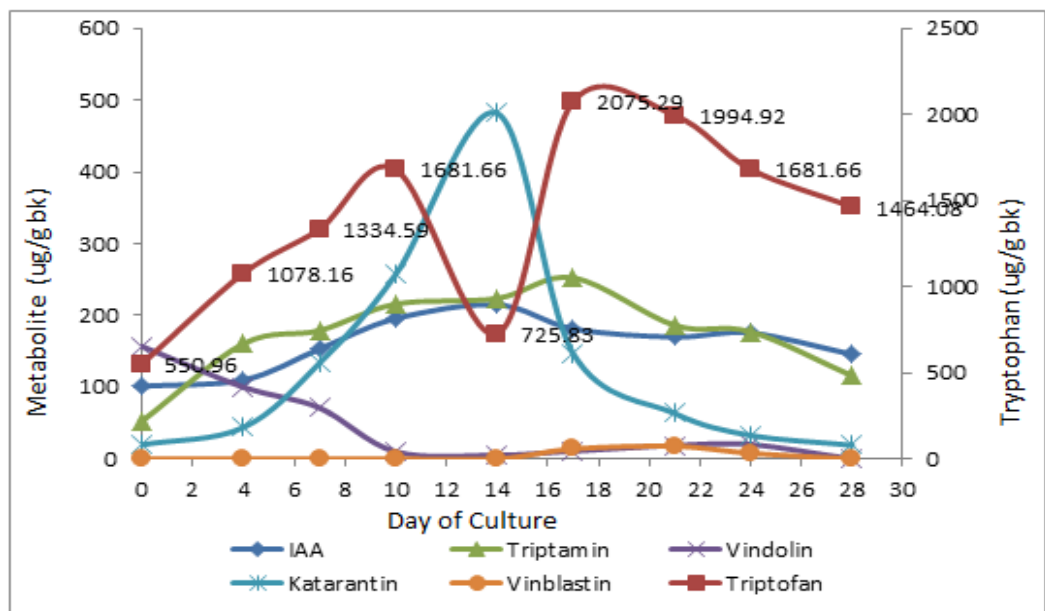

Figure 2: Graph metabolite content ( $\mu \mathrm{g} / \mathrm{g} \mathrm{dw})$ of vinka (C. roseus) aggregate cells in Erlenmeyer with treated of $150 \mathrm{mg} / \mathrm{L}$ tryptophan or $\mathrm{T} 3$

Catharanthine production is strongly influenced by the addition of wet weight (growth) is optimal. This study proves positive correlation supports an increase in the content of the Erlenmeyer catharanthine with growth of 0.75 (Table 1). Utilization of the addition of precursor tryptophan content on growth and optimum catharanthine be proved as stated in the hypothesis. Mutually supportive relationship between growth and secondary metabolite content of the treated tryptophan is supported by other studies such as Zhao et al., (2001b) and Dahab and El-Aziz, (2006). Yet another study on the contrary, an increase in secondary metabolites are not in line with the growth (Noli, 2004; Gaines, 2004). Precursor tryptophan optimal treatment on the growth and catharanthine content is approximately 150 $\mathrm{mg} / \mathrm{L}$ to $200 \mathrm{mg} / \mathrm{L}$ on day 14 after culture in Erlenmeyer and day 10 at $1.5 \mathrm{~L}$ airlift bioreactor. These findings will be very useful for large-scale production of catharanthine on the use of a continuous system, which requires the presence of good growth with optimal metabolite content.

Cell types and subcultures also important catharanthine affect the content of the treated tryptophan (Rijhwani and Shanks, 2008). Callus and suspension cells have been studied and compared by Wilkens et al., (2005) and stated that both cell types contain different secondary metabolites. The content of the suspension is lower than the secondary metabolite content of the callus. The decline has to do with the time prolonged subculture. Observations on the control start of a new phase I callus was subcultured 2-4 times in a solid medium. Phase II trial of new cell aggregate approximately 8 times subculture. Experiment IV to VI have been subcultured repeatedly to multiply callus (about 1 year more, or about 22 times the subculture). The measurement results of the third phase shows a decrease in the content of the content of vinblastine catharanthine even on long subculture became undetectable. The content catharanthine successively reduced in the other cell types of intact plant cells to aggregate into cell callus and suspension cells per gram dry weight similar to the control. But with treatment catharanthine tryptophan content can be increased in all cell types with different percentages.
Pattern catharanthine content in cultured cell aggregates in culture flasks and bioreactor after 14 days have different patterns. Day 14 in Erlenmeyer showed maximum content, but the content of the bioreactor is not optimal. Maximum content of the bioreactor would occur on the 10th day after culture. The difference is caused by the aeration system, the availability of $\mathrm{CO} 2$, the presence of $\mathrm{O} 2, \mathrm{pH}$ and pressure that appears in $100 \mathrm{~mL}$ Erlenmeyer flask and airlift bioreactor of $1.5 \mathrm{~L}$ is different. According Hvoslef-Eide, et al. (2005) that changes in different $\mathrm{pH}$ between flask and bioreactor which shows that there are differences in other growth factors. Also reported different patterns of growth both through the measurement of wet weight and dry weight of cells. This is also reflected in the study.

\section{Conclusions}

The relation between the increasing of catharanthine content with other secondary metabolites were 2 correlation. The negative correlation or antagonist that is vindolineafter being treated tryptophan. The positive correlation or synergistic ie tryptamine and IAA, vinblastine after being treated tryptophan.

This study has shortcomings in the use of tools to observe the cell growth that employed only a still camera on a microscope. In the next study we will utilize camera recorder to record the process of cell specialization dynamically after tryptophan treatment. Besides, it should also be investigated how the catharanthine content increase due to tryptophan treatment relates to other secondary metabolites on the same culture or cell aggregate culture of Catharanthus roseus.

\section{Acknowledgment}

The authors would like to thank the Ministry of Education and Culture of the Republic of Indonesia for funding this research through Sam Ratulangi University 2014 budget (DIPA) No. 0748/023-04.2.01/27/2013, dated December 9, 2013. 


\section{International Journal of Science and Research (IJSR) \\ ISSN (Online): 2319-7064}

Index Copernicus Value (2013): 6.14 | Impact Factor (2014): 5.611

\section{References}

[1] R. Alexandrova, I. Alexandrova, M. Velcheva, and T. Varadinova, "Phytoproduct and Cancer," Exp Pathol Parasitol, vol. 4, pp. 15-26, 2000.

[2] L. S. dePadua, N. Bunyapraphatsara, and R. H. M. J. Lemmens, "Plant Resources of South East Asia No. 12(1). Medicinal and Poisonous Plants 1," Bogor, Indonesia: PROSEA Foundation, 1999.

[3] A. Dutta, J. Batra, S. Pandey-Rai, D. Singh, S. Kumar, and J. Sen, "Expression of terpenoid indole alkaloid biosynthetic pathway genes corresponds to accumulation of related alkaloids in Catharanthus roseus (L.) G. Don," Planta, vol. 220, pp. 376-383, 2005.

[4] H. Sutarno and S. U. Rudjiman, "Catharanthus roseus (L.) G. Don," in Plant Resources of South-East Asia No. 12(1): Medicinal and poisonous plants 1, L. S. dePadua, N. Bunyapraphatsara, and R. H. M. J. Lemmens, Eds. Leiden, Netherlands: Backhuys Publisher, 1999, pp. 185-190.

[5] D. Pandiangan, R. R. Esyanti, V. Usviany, and W. Wulansari, "Production of Catharanthine in Catharanthus roseus Aggregate Cell Cultures by Feeding, Elicitation and Immobilization Method," in Proceedings of the International Conference on Mathematics and Natural Sciences (ICMNS), Bandung, Indonesia, 2008, pp. 379-386.

[6] D. Pandiangan, D. Rompas, H. Aritonang, R. Esyanti, and E. Marwani, "The Influence of Tryptophan on Growth and Catharanthine Content in C. roseus Callus Culture," Jurnal Matematika dan Sains, vol. 11, pp. 111-118, 2006 (in Indonesian).

[7] O. A. Moreno-Valenzuela, R. M. Galaz-Avalos, Y. Minero-GarcÃ-a, and V. M. Loyola-Vargas, "Effect of differentiation on the regulation of indole alkaloid production in Catharanthus roseus hairy roots," Plant Cell Reports, vol. 18, pp. 99-104, 1998.

[8] P.A. Girod and J.-P. Zryd, "Secondary metabolism in cultured red beet (Beta vulgaris L.) cells: Differential regulation of betaxanthin and betacyanin biosynthesis," Plant Cell, Tissue and Organ Culture, vol. 25, pp. 1-12, 1991.

[9] S. Kim, K. Jung, S. Kwak, and J. Liu, "Relationship between cell morphology and indole alkaloid production in suspension cultures of Catharanthus roseus," Plant Cell Reports, vol. 14, pp. 23-26, 1994.

[10]D. Pandiangan, W. Tilaar, Karyono, R. R. Esyanti, and A. Subarnas, "The Growth, Protein Content and TDC Activity Responses of Catharanthus roseus (L) G. Don Cell Aggregate Culture that Feeding Tryptophan," Bionatura vol. 13, pp. 16-25, 2011 (in Indonesian).

[11]D. Pandiangan and N. Nainggolan, "Alkaloid Production from Catharanthus roseus Callus," Jurnal Ilmiah Sains, vol. 6, pp. 48-54, 2006 (in Indonesian).

[12]D. Pandiangan, W. Tilaar, and N. Nainggolan, "The Correlation of Cell Specialization with IAA Content of Catharanthus roseus Cell Culture by the Addition of Tryptophan," Eugenia, vol. 18, pp. 140-149, 2012 (in Indonesian).

[13] N. N. Darsini, "The Development of Laticifer on Callus Culture Catharanthus Roseus (L) G Don which were Induced by Plant Growth Regulator Combination
Kinetin + NAA," J Biol, vol. 15, pp. 34 - 38, 2011 (in Indonesian).

[14]D. L. Nelson and M. M. Cox, Lehninger Principles of Biochemistry, fourth ed.: W. H. Freeman, 2004.

[15] J.Zhao, Q. Hu, Y.Q. Guo, W.H. Zhu. 2001b. Effects of stress factors, bioregulators, and synthetic precursors on indole alkaloid production in compact callus clusters cultures of Catharanthus roseus. Appl Microbiol Biotechnol. 55(6):693-8.

[16] J.C.Thomas , D. C. Adams, C.L. Nessler, J. K. Brown, and H. J. Bohnert. 1 995. Tryptophan Decarboxylase, Reproduction of the Tryptamine, and Whitefly. Plant Physiol. 109: 71 7-720

[17] K.M.Oksman-Caldentey , S.T. Häkkinen and H. Rischer. 2007. Metabolic engineering of the alkaloid biosynthesis in plants: functional genomics approaches. In: R. Verpoorte, A.W. Alfermann, T.S.Johnson(Eds). Applications of Plant Metabolic Engineering.pp. 109. 127. Published by Springer, P.O. Box 17, 3300 AA Dordrecht, Netherlands.

[18] S. Whitmer, R. van der Heijden, R. Verpoorte. 2002. Effect of precursor feeding on alkaloid accumulation by a tryptophan decarboxylase over-expressing transgenic cell line T22 of Catharanthu roseus. J Biotechnol. 96 (2) : 193-203

[19] M. Vanisree, C. Y. Lee, S. F. Lo, S. M. Nalawade, C. Y. Lin, and H. S. Tsay. 2004a. Studies on The Production of Some Important Secondary Metabolites 1 Bot. Bull. Acad. Sin. 45: 1-22.

[20] M.Vanisree, H. Sin, and H.S. Tsay. (2004b) Plant Cell Cultures : An Alternative and Efficient Source for the Production of Biologically Important Secondary Metabolites. International Journal of Applied Science and Engineering. 2,1:29-48.

[21] E.Mccoy and E. Sarah. 2006. Directed biosynthesis of alkaloid analisys in the medicinal palntCatharanthusroseus. J. Am. Chem. Soc., 128(44), 14276-14277.

[22]K.Y.Paek, D. Chakrabarty and E.J. Hahn. 2005.Application of bioreaktor systems for large scale production of horticultural and medicinal plants. Plant Cell, Tissue and Organ Culture81: 287-300 